\title{
A Comparative Study on Behavioral Problems of Preschool Children among Working and Non-Working Mothers
}

\author{
${ }^{1}$ Mrs. Ancy Alexander, ${ }^{2}$ Dr Asha P Shetty* \\ ${ }^{I}$ Post Graduate, Department of Paediatric Nursing, K. Pandyarajah Ballal Nursing Institute \\ Ullal, Mangalore 575020, Karnataka, India \\ ${ }^{2}$ Professor and HOD, Dept of Paediatric Nursing, Yenepoya Nursing College \\ Yenepoya University, Deralakatte, Mangalore 575018, Karnataka, India
}

\begin{abstract}
:
Introduction: Children are the nation's most important assets. Preschool period is a fantastic time for a child to learn things. At the same time, they become easily frustrated. A large number of children suffer from behavioral problems at one time or the other during their development. Mothers should try to devote some time for their children to make them feel loved and special. Mothers should be able to detect any behavioral changes at the earliest.

Objectives: The objectives of the study were to assess the behavioral problems of preschool children among working mothers, assess the behavioral problems of preschool children among non-working mothers, compare the behavioral problems of preschool children between working and non working mothers and find out the association between behavioral problems of preschool children with selected demographic variables.
\end{abstract}

Design: Non-experimental comparative survey design.

Setting: Smart Kids Play School, Bharati English Medium School and Holy Angels Higher Primary School, Mangalore

Sample: 30 working and 30 non-working mothers of pre-school children

Interventions: Demographic Proforma and Behavioral Problems Assessment Rating Scale were administered to both working and non-working mothers.

Results: Mild level of behavioral problems were reported by $40 \%$ of working mothers and $83.3 \%$ of nonworking mothers, whereas $16.7 \%$ of non-working mothers and $60 \%$ of working mothers reported moderate level among their children. There was significant difference in the level of behavioral problems of preschool children among working and non-working mothers. There was significant association between behavioral problems of preschool children and gender of the child. There was also significant association between behavioral problems of preschool children among working mothers and age of the child.

Conclusion: Preschool children of working mothers have more behavioral problems than those of nonworking mothers. Nurses can play a major role in diminishing the behavioral problems by providing guidance and counseling for the children and their mothers.

Keywords: Behavioral problems, preschool children, working and non-working mothers

\section{Introduction}

Children are the inheritance from God. They are like clay in the potter's hand. Handled with love and care, they become something beautiful or else they will break. ${ }^{1}$ Every child should have tender loving care and sense of security from parents. The mother is more responsible for the integrated development of a child. ${ }^{2}$

Preschool children are of paramount importance in determining the future behaviors of children. Preschool behavior problems are now being recognized as clear indicator of difficulties that may persist into later childhood. ${ }^{3}$ Recent evidence by WHO indicates that by 2020 childhood psychiatric disorders will rise over $50 \% .{ }^{4}$ It may be due to genetic, psychological or environmental factors of the child.

A study conducted on behavior problems among preschool children in New Delhi revealed that $22 \%$ of them had behavioral problems. ${ }^{5}$ The National Survey on Drug Use and Health Report states that during the past two decades, there have been marked changes in inpatient services for preschool children with behavioral problems. ${ }^{3}$ Some disorders are more common than others, and conditions range from mild to severe. The common behavioral problems identified in children includes Habit problems, Problems of eating, Sleep problems, Speech problems, Scholastic problems, Psychosexual problems, Personality problems and Psycho social problems. ${ }^{6}$ Often, a child will be having more than one disorder.

Working women will have less time at her disposal for child care. The working mother has both positive and negative impact over the child's development. Hence the researcher intended to identify behavioral problems of preschool children of working mothers and to compare with that of non-working mothers. An 
awareness of the prevalence of these problems is important to plan mental health services for children in order to improve the quality of life of the affected children.

\section{The Objectives of the study were to:}

1. assess the behavioral problems of preschool children among working mothers.

2. assess the behavioral problems of preschool children among non-working mothers.

3. compare the behavioral problems of preschool children between working and non working mothers.

4. find out the association between behavioral problems of preschool children with selected demographic variables.

\section{Hypotheses}

The following hypotheses were tested at 0.05 level of significance

$\mathrm{H}_{1}$ : There will be significant difference in the level of behavioral problems of preschool children among working and non- working mothers.

$\mathrm{H}_{2}$ : There will be significant association between the level of behavioral problems of preschool children among working and non working mothers and their selected demographic variables.

\section{Materials And Methods}

Non-experimental comparative survey design was used in this study. Demographic Proforma and Behavioral Problems Assessment Rating Scale were administered to mothers to assess behavioral problems of preschool children.Behavioral Problems Assessment Rating Scale consists of 50 items. The content was categorized into 8 areas such as Habit Problems, Problems of eating, Sleep Problems, Speech Problems, Scholastic Problems, Psychosexual Problems, Personality Problems and Psycho Social Problems. The items were scored under five point scale as never, occasionally, seldom, frequently and always with scores of one, two, three, four and five respectively. The obtained reliability coefficient alpha (Cronbach's alpha) $r=0.89$. Written consent was obtained from the mothers selected for the study. The main study was conducted among 30 working and 30 non-working mothers of pre-school children at Smart Kids Play School, Bharati English Medium School and Holy Angels Higher Primary School. Non probability purposive sampling technique was used to select the sample for the study. Both descriptive and inferential statistics were used to analyze the data.

\section{Results}

Description of mothers according to the working status showed that there were equal number (50\%) of working and non-working mothers $(50 \%)$. Majority of working mothers $(63.3 \%)$ were working in private sector. Highest percentage i.e. $80 \%$ of working mothers and $56 \%$ of non-working mothers were Hindus. Majority i.e. $30 \%$ of working mothers and $53.3 \%$ of non-working mothers were educated to primary level and high school respectively.

Among working mothers selected for the study, majority (43.3\%) of them had a monthly income below Rs.5000, whereas $43.3 \%$ of non-working mothers had a monthly income between Rs.5001 and Rs.10, 000. Highest percentage i.e. $43.3 \%$ of working mothers and $46.7 \%$ of non-working mothers were having two children. Data regarding the type of family showed that the maximum i.e. $53.3 \%$ of working mothers and $46.7 \%$ of non-working mothers belonged to nuclear family and joint family respectively.

Description of preschool children according to their age revealed that the highest percentage i.e. $36.7 \%$ of children of working mothers and $40 \%$ of non-working mothers belonged to the age group of 3 years and 5 years respectively. Maximum (56.7\%) of children of working mothers were males whereas there were equal number of males and females (50\%) among preschool children of non-working mothers. Majority i.e. $46.7 \%$ of preschool children of working mothers and 53.3\% of non-working mothers were studying in LKG and Pre K.G respectively. Highest percentage i.e. $46.7 \%$ of children of working mothers and $60 \%$ of non-working mothers were reported as first born child.

Assessment of behavioral problems of preschool children among working mothers revealed that $40 \%$ were having mild level of behavioral problems and majority, $60 \%$ were having moderate level of behavioral problems. The mean percentage of behavioral problems of preschool children among working mothers was 44.11 with a mean $110.27 \pm 17.710$.

Assessment of behavioral problems of preschool children among non-working mothers revealed that $83.3 \%$ were having mild level of behavioral problems and majority, $16.7 \%$ were having moderate level of behavioral problems. The mean percentage of behavioral problems of preschool children among working mothers was 33.59 with a mean $83.97 \pm 21.458$. Level of Behavioral Problems of Preschool Children among Working and Non-working Mothers is shown in fig.1 


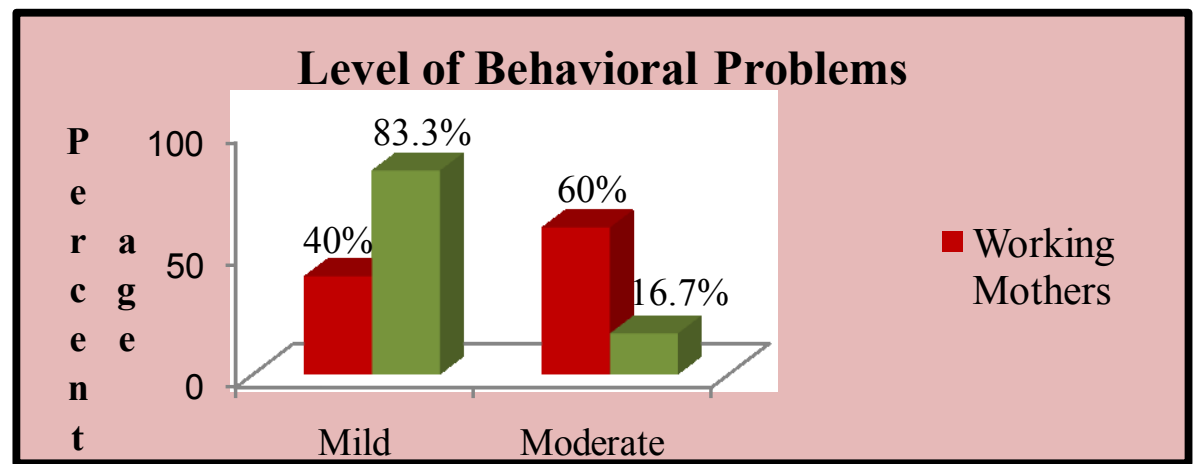

Figure 1: Bar diagram showing the level of behavioral problems among preschool children of working and nonworking mothers.

Unpaired ' $\mathrm{t}$ ' value[ $(\mathrm{t}=5.177)$ at 0.05 level of significance] unveiled that there was significance of difference between behavioral problems of pre-school children among working and non-working mothers (table $1)$.

Table 1: Mean, Standard Deviation, Mean difference, Standard Error and ' $t$ ' value of level of behavioral problems of Preschool Children among Working and Non-Working Mothers. $\mathrm{N}=60$

\begin{tabular}{|c|c|c|c|c|c|c|c|c|}
\hline $\begin{array}{l}\text { Sl. } \\
\text { No }\end{array}$ & Group & Mean & SD & Mean Difference & $\begin{array}{l}\text { Standard } \\
\text { (SE) }\end{array}$ & Error & df & t value \\
\hline 1 & Working Mothers & 110.27 & 17.71 & & & & & \\
\hline 2 & Non-working Mothers & 83.97 & 21.46 & 26.300 & 5.080 & & 58 & $5.177 *$ \\
\hline
\end{tabular}

There was significant association between behavioral problems of preschool children among working mothers and age and gender of the child( table 2).

Table 2: Chi square test to find association between the behavioral problems of preschool children and demographic variables such as age and gender of working mothers $\mathrm{N}=30$

\begin{tabular}{|c|c|c|c|c|c|c|}
\hline S.No & Demographic Variables & $\begin{array}{l}\text { Median } \\
(<118)\end{array}$ & $\begin{array}{l}\text { Median } \\
(\geq 118)\end{array}$ & $\begin{array}{l}\text { Chi square } \\
\text { Value }\left(\chi^{2}\right)\end{array}$ & df value & P value \\
\hline 1 & $\begin{array}{l}\text { Age (in years) } \\
3 \text { and } 4 \\
5\end{array}$ & $\begin{array}{l}4 \\
8\end{array}$ & $\begin{array}{l}16 \\
2\end{array}$ & 7.656 & 1 & $0.006^{*}$ \\
\hline 2 & $\begin{array}{l}\text { Gender } \\
\text { Male } \\
\text { female }\end{array}$ & $\begin{array}{l}3 \\
9\end{array}$ & $\begin{array}{l}14 \\
4\end{array}$ & 6.160 & 1 & $0.013^{*}$ \\
\hline
\end{tabular}

$\chi_{(1)}^{2}=3.84 ; P \leq 0.05$

There is significant association between behavioral problems of preschool children among nonworking mothers and gender of the child. (table 3 ).

Table 3: Chi square test to find association between the behavioral problems of preschool children and demographic variables such as gender of non-working mothers $\mathrm{N}=30$

\begin{tabular}{lllllll}
\hline S.No & Demographic Variables & $\begin{array}{l}\text { Median } \\
(<\mathbf{1 1 8})\end{array}$ & $\begin{array}{l}\text { Median } \\
(\geq \mathbf{1 1 8})\end{array}$ & $\begin{array}{l}\text { Chi square } \\
\text { Value }\left(\chi^{2}\right)\end{array}$ & $\begin{array}{l}\text { df } \\
\text { value }\end{array}$ & P value \\
\hline 1 & $\begin{array}{l}\text { Gender } \\
\text { Male } \\
\text { female }\end{array}$ & 4 & 11 & 4.800 & 1 & $0.029^{*}$ \\
& 11 & 4 & & & \\
\hline & $\mathbf{3 . 8 4} ; \mathbf{P}<\mathbf{0 . 0 5}$ & & & &
\end{tabular}

$\chi_{(1)}^{2}=3.84 ; \mathbf{P} \leq 0.05$

\section{Discussion}

Assessment of behavioral problems of preschool children among working mothers revealed that $40 \%$ were having mild level of behavioral problems and $60 \%$ were having moderate level of behavioral problems. Consistent findings were found in study conducted by Divya which revealed that majority $(89.34 \%)$ of the children of working mothers had moderate level of behavioral problems and only $10.66 \%$ had mild level of behavioral problems. ${ }^{7}$

Assessment of behavioral problems of preschool children among non-working mothers revealed that $83.3 \%$ were having mild level of behavioral problems and $16.7 \%$ were having moderate level of behavioral 
problems. Similar findings were reported by Divya indicates that highest percentage (90\%) of children of nonworking mothers had mild psychosocial problems and remaining $10 \%$ of them had moderate psychosocial problems. ${ }^{8}$

Unpaired ' $\mathrm{t}$ ' value[ ( $\mathrm{t}=5.177)$ at 0.05 level of significance] unveiled that there was significance of difference between behavioral problems of pre-school children among working and non-working mothers. Findings of the present study supported by Anitha (2010) revealed that there was significant difference in the level of behavioral problems of preschool children among employed and unemployed mothers ( $t$ value is 6.348 ; $\mathrm{p}<0.05$ level $)^{9}$

Computed chi-square $\left(\chi^{2}\right)$ revealed a significant association between behavioral problems of preschool children of working mothers and age and gender of the child $\left(\chi^{2}=0.006, \chi^{2}=0.013\right.$ at 0.05 level of significance). There was also significant association between behavioral problems of preschool children of non-working mothers and gender of the child. ( $\chi^{2}=0.029$ at 0.05 level of significance). Findings of the present study are in congruent with the study conducted by Divya (2008). Age of the child, gender, number of children, type of family and birth order showed a significant association $(p<0.05)$ with the behavioral problems of children of working mothers ${ }^{7}$.

\section{Implications}

Nurses can play a major role in diminishing the behavioral problems by providing education, guidance and counseling to the mothers and children and also by creating good environment for them. Nurse researchers can be motivated to develop new strategies to prevent the behavioral problems of preschool children.

\section{Conclusion}

This study results indicates the need to be aware of the behavioral problems of preschool children. Screening is necessary to detect behavioral problems in preschool children. Therefore behavioral problems always require special attention.

\section{Acknowledgements}

My heartfelt thanks to Prof.(Mrs.) Asha P Shetty, Mr. Praveen V Bagali, management and faculty of KPBNI, my batch mates and working and non-working mothers who participated in this study. I also thank all those who had helped us directly or indirectly to carry out this study.

\section{References}

[1]. Vijayalakshmi K, Kumar CV, Rajamanickam H, Cherian A. Child rearing practices and psychological problems in children. Nursing and Midwifery Research Journal 2007 Apr; 3(2):49-51.

[2]. Datta P. Pediatric Nursing. $2^{\text {nd }}$ edition. New Delhi: Jaypee Brothers Medical Publishers (P) Ltd; 2009.p.1, $186-192$.

[3]. Perera H, Gunatunge C. Screening for mental health problems in urban preschool children- A pilot study. Sri Lanka Journal of Child Health 2004; 33 (2):39-42.

[4]. Duhan, Kaur P. Mental health promotion for school children. A manual for school teachers and school health workers. Regional office for the Eastern Mediterranean. Indian Psychological Review 2000; 122: 193-5.

[5]. Rai S, Malik SC, Sharma D. Behavior problems among preschool children. Indian Pediatrics 1993; 30(4):475-8.

[6]. Gupte S. The Short Textbook of Pediatrics. 10 $0^{\text {th }}$ edition. NewDelhi: Jaypee Publications; 2004.

[7]. Divya A. A study to assess emotional and behavioral problems of children (6-12 years) of working mothers in selected schools, Mangalore. Unpublished dissertation submitted to RGUHS. 2009.

[8]. Thomas D. A comparative study to assess the Psychosocial Problems of Children [8-12 years] of working and non-working mothers in selected hospital at Tumkur. Unpublished dissertation submitted to RGUHS, Bangalore 2010.

[9]. Anitha J, Jayasudha A, Kalaiselvi. Behavioral problems among preschool children. Nightingale Nursing times 2010 Jul; 6(4):33-36. 